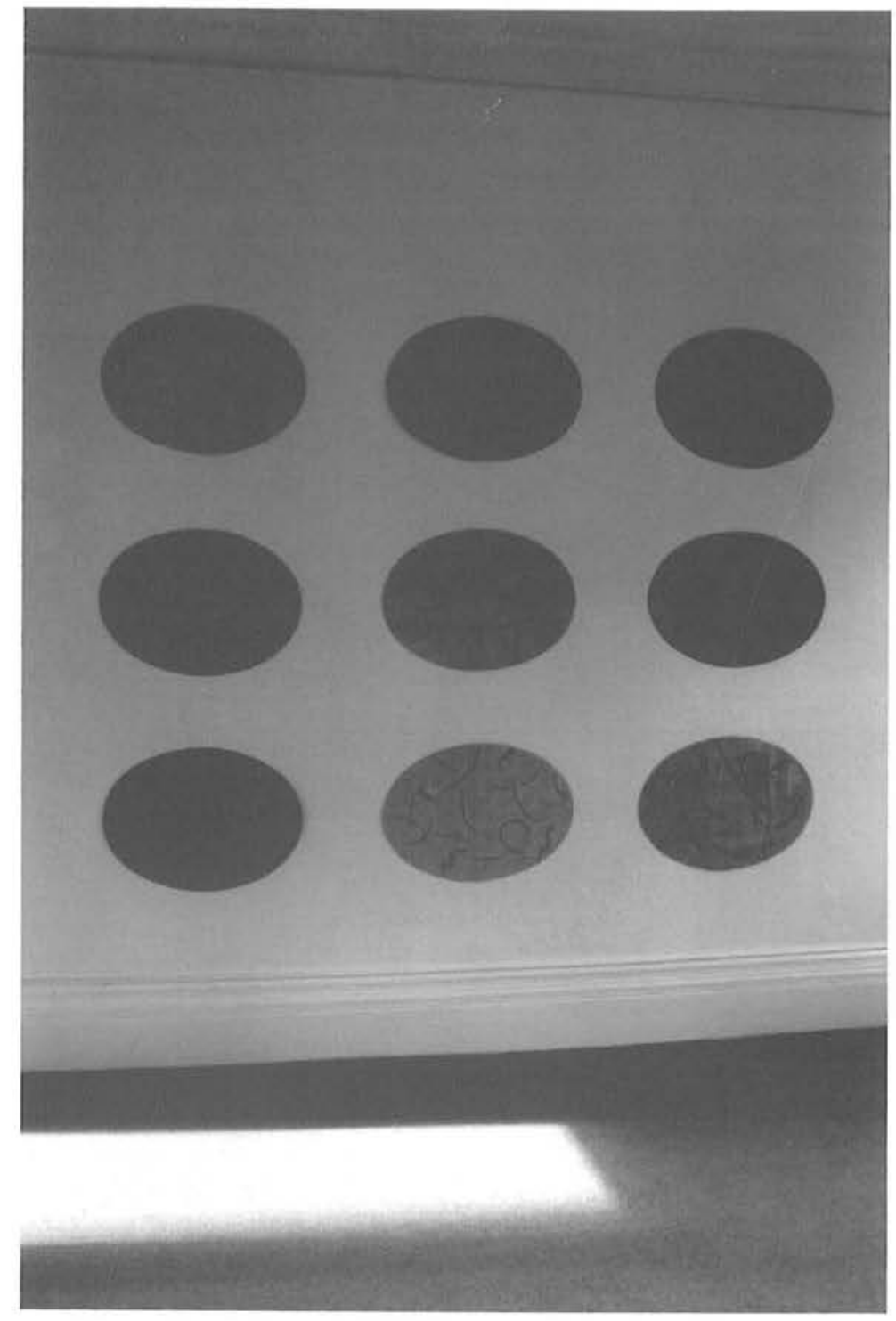




\title{
Lamella: a spacing of skin and distant boundaries
}

\author{
Sarah Treadwell
}

Recent works by Barbara Tuck, a series entitled Lamella, consist of groups of nine elliptical skins of painted aluminium. Each Lamella, the parts and the whole, is desirable, difficult and excessive; arousing the passions of the collector and refusing attributes of value. No frames to set apart or emphasise and no secret fixings to mark the artist as magician; the Lamella barely adhere to the wall surface.

They seem marginally located in art categories although participating, somewhat uneasily, in the conventions of the field; they are to be attached to walls in varying arrangements of the nine parts and can be described as oil paintings though on aluminium not canvas. The Lamella, membranes or gills, refer to the morphological not only through their naming, spreading out beyond the boundaries of the discipline that attempts to house them.

A calligraphic surface passes across the constrained shapes of the elliptical Lamella. The ovals 
suggesting an imperfect origin, egg or womb, a distorted circle or stretched sphere straining the credibility of an originary I (the gestures of authorship are repressed and suggested in these works); a straining of an eye which locates a body in relationship to a surface gaze. The Lamella consists of unstable imperfections, ellipses which only the positioning of the body in space utilizing the laws of perspective can restore to the perfection of the circle (here the physical corrects or creates the ideal instead of the usual perfection of theory). The observer, a material body in space, can create the Platonic satisfaction of a circle but only fleetingly and at the expense of giddiness and disorientation utterly aware of the separation between mind and body.

The geometries of the Lamella, the repeated ellipses, and the regular patternings that they seem to resist, invite a biological reference. An egg contains a germ of future life but in the Lamella it is not a pristine new beginning nor a unique mark but rather an inevitable re-run of information contained in patterns that imprint the egg. Potential new beginnings are smothered in over-arching decorative patterns. Between the shape and the surface of the Lamella is a plane of slippage; a lack of conjunction between skin and body. Ornamental narratives flow over individual lamella; the Lamellae themselves create a field within which the individual is both marked and lost. Registered in ellipsis is an absence, "the omission of one or more words in a sentence, which would be needed to express the sense completely ... " $;$ the works remain open in meaning and spatial configuration.

In Lamella no VII the nine pieces that make up the work are all different and separate but with internal references. Two milky egg shell blue lamellae, with a surface calligraphy that scrapes through to the tissue/flesh beneath, like twins, set up possibilities of pairing. But one is a pale reflection of the other; the body beneath the skin less bloody. A ghost constructed in a different focus, in a different layer, straining the eyes of the viewer, warping the surface of the wall to which they lightly adhere. In Lamella no VII the pairing off continues; the 
sameness of two brick ochre dusty lamellae qualified by a difference that destabilizes the structure of the whole. Thus the control and clarity of the surface marks disintegrates the pairings; the surface skin is rumpled by a calligraphy cutting through to differing layers of chalky bone.

This is not "the nihilistic gesture of attempting to counter totality with the assertion of unmediated singularity or individuality" but rather "...[a] dwell[ing] on the possibility of thinking unity or totality beyond the determination of synthesis and therefore beyond a projected or posited essence and thus in terms of the possibility of unity/totality being the belonging together of the different; a fundamental and constitutive part of which will be distance." 2

In the pairings and groupings within the Lamella familial connections and failures of connection are constructed. The distance between parts created by a shifting surface focus, contrasting tonal shifts and foreign hues. There is also, over-riding the internal arrangements, a stream of words, a babble of signs that momentarily adhere to the surface of the Lamella but seem to refer to another level of discourse. A distant other level beyond the particular individual case of ellipse or grouping of ellipses; a realm of writing.

The surface calligraphy is a writing that invites interpretation but also suggests the loss of a conscious will to decipher that subsumes meaning into form. The writing of a language that is unknowable, a babble that offers amnesia of form as an escape, into pattern, texture, colour and arrangement, into drawing. But as Catherine Ingraham points out "writing and drawing are exactly the same from a textuality standpoint. Neither are linear structures, neither are representational in the way that they claim. ${ }^{\prime 3}$ The drawings of the writing on the Lamella suppress the differences that conventionally structure their separate 'reading' techniques. Denial of the hand-writing continues in the making of these paintings, a process that 
eschews presence; the signature is buried in the automatic action of the roller that skims the aluminium surface which gives no resistance. The grain of canvas is absent and the working of self into the material of the Lamella is reduced.

The calligraphic form seems to insist on being read; marks of writing score the

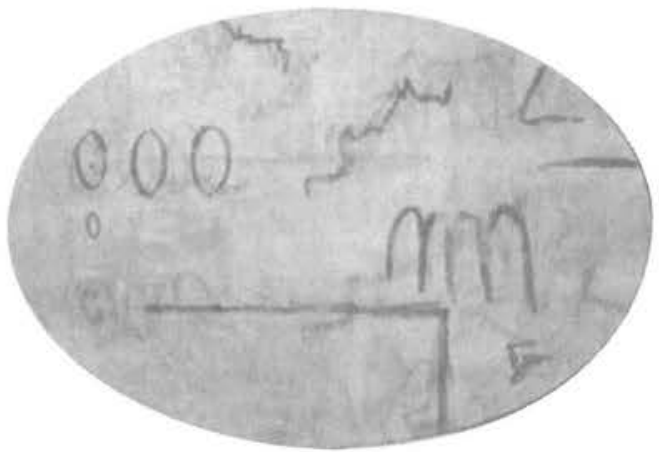
surface skin. The lines of writing are interrupted and also continued by the conventional notation of architectural drawing, drawings that defer to materiality while structuring the physical. These partial plans and sections that cause an "interruption of "linear writing by drawing, spatiality, volumetrics, may also be a moment of breach that is inevitably sexual (the imprint of the body or shape on the clean page.) ${ }^{\prime 4}$ The repetition of representation of the physical indicatesthe convoluted boundary between writing and spatiality; the marks of architectural drawing depending on formal qualities, the enclosing boundary, the turned shoulder. In the Lamella surface marks cannot be separated from the body. The body is marked by writing, a double writing that is constructed from the forms of presence.

That the works shifts between the surface/skin and the body refusing any simple separation of the two is recognized by the inclusion of Lamella no IV in an exhibition Surface Tension and the description of the works by the the curator; "These artists, then, are no longer charged with stripping away the outer and unnecessary trappings of art to reveal its essence, but rather, they are engaged in a constant play between a surface and that which putatively lies beneath it." 5 The "play between" in the case of the Lamella seems to be through a negotiation 
of boundaries; apparent in the refusal to separate writing and, the marks of materiality, architectural writing. And in the swelling and contracting of the boundaries of the ellipses by the presence of a viewer; distortions of perfection. The boundaries between the enclosures of the ellipses and the fields of surface patterning that flow above them are also problematic as are those that govern the scale of ornamentation in relationship to size.

The surface of the Lamella seem to endlessly assert and withdraw from the act of enclosure, the formation of boundaries. Elbows, small L shape marks, construct corners that jab at the surface of the pieces. The corners, vestiges of contained space, acts of containment that creates an interior and an exterior, are places to dwell and to hold. "The constitution of the house necessitates distance. In addition it demands the experience of that distance. The experience of dwelling is, though in an as yet to be specified way, premised upon the experience of distance." 6 The Lamella, spaced out across the wall, concerned with relationships of distance and space, marked with gestures of containment written in an architectural language, can be seen to construct relationships of dwelling. The house, dependent on distance to separate floor from floor and room from room, is held together by corners. Corners are the outcome of collisions; the meeting of lines of distance and difference that the ellipse and the circle cannot acknowledge. In a circle all becomes one and the ellipse is an uneasy expression of unity but unity nevertheless whereas the corner, the place of disgrace, of secrets and security, is a point of accumulation and weakness where planes joined for strength can be prised apart; the corner is redolent of separation.

The incisions of calligraphy separate the surface of paint, splitting it to reveal an inner and create an outer layer. Writing, calligraphy cutting into the surface, like tattoo, violates and constructs the surface of skin; the boundary of the body is at risk, an opening or orifice created or revealed. The surface puckered and flaking; magnified, a piece of reptilian skin proffers up a decorative, physical and irritable surface. Excesses of colour, over-sized tex- 
ture, an enlargement of matter pushing the limits of reason and the restrained boundaries of taste.

Excess wells up beneath the surface; like the marks of thumbprints on the body the surface reveals a bruising. A welling up of drops of blood that coagulate and congeal, marks of possession and ownership, a signature. The fluidity of the Lamellae is also transgressive of boundaries; drops of gold, blood and tears seep and exude through boundaries passing through a moment of perfection; the parts and the collection in a continuous flow. The surface of the works, a plane of evaluation, is in flux, the layers shifting. Like floaters that drift across the retina disturbing vision, the Lamella unsettle the "truth" of vision.

"Since non-meaning falls within the purview of the understanding it does not mark its limit. The limit will not be an absolute but rather exist as a site of tension at which in spite of its being present the understanding can no longer be said to dominate."

The Lamella is shadowed by itself, an anamorphic version of the sphere, the tracings and displacements of an impossible perfection. ${ }^{7}$ The construction of the ellipse involves a division, a slicing of the circle, construction of displaced centres, a transferral of measurement leading to a multiplication of circles (displaced progenies in the image of their father). The new figure, the ellipse, is delineated by tracing the boundary that tangentially touches these displaced circles; the ellipse founded on an iteration and alteration of a structuring circle. In the Lamella the geometry of the ellipse acknowledges connections to

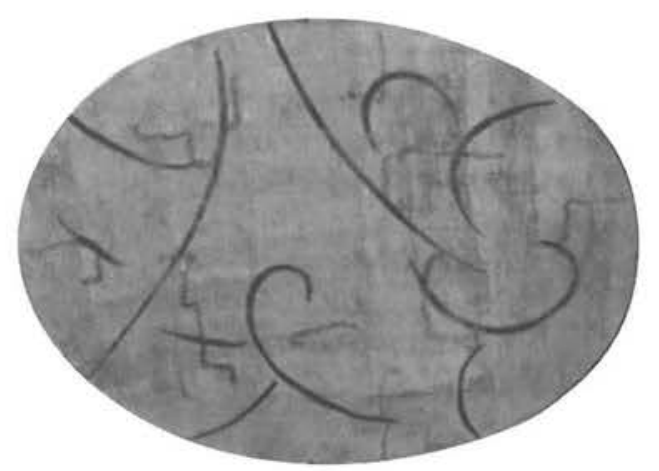


founding orders but also threatens to expand past its own formation, its expansiveness cannot be contained. In the process of construction, criss-crossing the dissection of a circle, the Lamella, germ of the material and maternal, begin to proliferate in a disturbing way.

\section{Notes:}

1

2
Shorter Oxford Dictionary 1973.

Andrew Benjamin, "Distancing and Spacing," in A. Benjamin (ed.), Philosophy and Architecture (London: Academy Editions, 1990), p. 7.

Catherine Ingraham, "Initial Proprieties: Architecture and the Space of the Line," in B. Colomina, (ed.) Sexuality and Space (Princeton: Princeton Architectural Press, 1992), p. 258.

Ibid.

Christina Barton, "At the surface: an introduction," Catalogue for exhibition "Surface Tension" (Auckland City Gallery, 1992), p. 3.

Andrew Benjamin, op. cit., p. 7.

In an interview Barbara Tuck discussed spheres in their anamorphic forms as eggs in work by Piero della Francesca, Pala di Brera, Milan. 
